\title{
POLARIZATION CHARACTERISTICS OF PACKED BED ELECTRODE REACTOR FOR ELECTROREDUCTION OF OXYGEN TO HYDROGEN PEROXIDE
}

\author{
MASAo SUDOH, Hisatsugu KITAGUCHI AND Kozo KOIDE \\ Department of Chemical Engineering, Shizuoka University, Hamamatsu 432
}

Key Words: Electrolysis, Packed Bed Electrode, Two Phase Model, Overpotential Profile, Hydrogen Peroxide

\begin{abstract}
The relation between current density and overpotential for electroreduction of oxygen to hydrogen peroxide in the packed-bed electrode reactor was studied. Theoretical analyses were made on the basis of the two-dimensional two-phase model of the particulate electrode where the distribution of concentration of dissolved oxygen and the overpotential were considered. The kinetics of electrode reactions was determined with a rotating-disk electrode of graphite. The effective specific surface area available for electrode reaction in the packed-bed electrode was determined by analysing the transient current response to a potential step. The observed values of overpotential profile and the polarization curves of the packed-bed electrode agreed with the theoretical ones calculated by use of the kinetic and reactor properties.
\end{abstract}

\section{Introduction}

Hydrogen peroxide can be produced to relatively high concentration by electroreduction of oxygen in an alkaline solution with a packed-bed electrode reactor. The packed-bed electrode reactor has the major advantages of large surface area available for electrode reaction and high mass transfer rate. Recently, potential profiles of the particulate electrode were examined with a two-phase model ${ }^{12)}$ by many investigators. ${ }^{1,2,6-9,13,19)}$ Most experimental conditions were limited to the case of neglecting the distributions of reactant concentration and the equilibrium potential in the particulate electrode. Only Stork et al. ${ }^{5,15)}$ investigated the potential profile of the particulate electrode with consideration of these distributions under the conditions of limiting current. However, investigation of the potential profile of the particulate electrode at various potentials for successive and competitive electrode reactions such as the reduction of oxygen has not been dealt with until now.

The purpose of this work is to clarify both experimentally and theoretically the current densityoverpotential curves of the packed-bed electrode for electroreduction of oxygen to hydrogen peroxide.

1. Theoretical

1.1 Electrode reaction

Cathodic reduction of oxygen in alkaline solution

Received January 10,1985. Correspondence concerning this article should be addressed to M. Sudoh. H. Kitaguchi is now at Nippon Steel Co., Lid., Kitakyushu 805. K. Koide is now at Dept of Chem. Eng., Tokyo Inst. of Tech., Tokyo 152.

on a graphite electrode proceeds by successive and competitive reactions as follows:

Reaction 1:

$$
\mathrm{O}_{2}+\mathrm{H}_{2} \mathrm{O}+2 \mathrm{e}^{-} \rightleftharpoons \mathrm{HO}_{2}^{-}+\mathrm{OH}^{-}
$$

Reaction 2:

$$
\mathrm{HO}_{2}^{-}+\mathrm{H}_{2} \mathrm{O}+2 \mathrm{e}^{-} \rightleftharpoons 3 \mathrm{OH}^{-}
$$

Since peroxide ion is the intermediate substance for the reduction of oxygen, it is possible for peroxide ion to accumulate to higher concentration when reaction 1 is faster than reaction 2.

1.2 Changes of equilibrium potential and overpotential

The current and the concentration of dissolved oxygen at the bed inlet show pseudo-steady state values at a certain time after electrolysis begins. In the present paper, the behavior of the reactor at pseudo-steady state is discussed.

The equilibrium potential is a function of the concentration of dissolved oxygen and peroxide ion. The equilibrium potential of reaction 2 is almost constant in the packed-bed electrode shown in Fig. 1 since the concentrations of peroxide ion and hydroxide ion at the bed inlet are sufficiently higher than the concentration changes of those ions throughout the bed. Meanwhile, the concentration of dissolved oxygen decreases along the liquid flow because of oxygen consumption by reaction 1 . The difference $\Delta E$ of the equilibrium potential from the initial value at the beginning of electrolysis is obtained on the basis of the Nernst equation.

$$
\Delta E=-(\boldsymbol{R} T / 2 \boldsymbol{F}) \ln \left(C_{A i}^{\infty} C_{B}^{\infty} / C_{A}^{\infty} C_{B i}^{\infty}\right)
$$



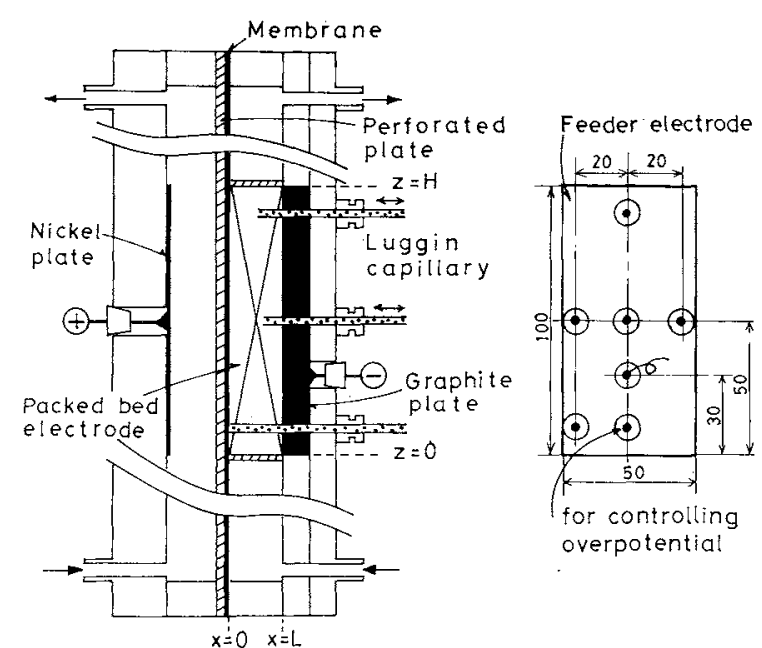

Fig. 1. Details of packed-bed electrode reactor and location of Luggin capillaries.

where $C_{A}^{\infty}$ and $C_{B}^{\infty}$, respectively, are the concentrations of dissolved oxygen and peroxide ion in the liquid bulk and the subscript $i$ indicates the initial value.

Actual overpotential $\eta$ at a certain reaction time is given by the following equation, modifying the change of equilibrium potential.

$\eta=\eta_{i}-\Delta E=\eta_{i}+(R T / 2 F) \ln \left(C_{A i}^{\infty} C_{B}^{\infty} / C_{A}^{\infty} C_{B i}^{\infty}\right)$

Strictly speaking, electrode reaction rate is a function of $\eta$, which cannot be measured directly but can be estimated by Eq. (4) with the measured value of the initial overpotential $\eta_{i}$ and $\Delta E$ calculated from $\mathrm{Eq}$. (3).

\subsection{Electrode reaction rates}

Electrode reaction rates of reactions 1 and 2 are given by the following equations, assuming first-order reaction rates for the concentrations of the reactants. ${ }^{11)}$

$$
\begin{aligned}
& -i_{1} / 2 \boldsymbol{F}=k_{A} C_{A}^{\circ} \exp \left(-\alpha_{1} \boldsymbol{F} \eta / \boldsymbol{R} T\right) \\
& -i_{2} / 2 \boldsymbol{F}=k_{B} C_{B}^{\circ} \exp \left(-\alpha_{2} \boldsymbol{F} \eta / \boldsymbol{R} T\right)
\end{aligned}
$$

where $i$ is the current density, $k$ the reaction rate constant and $\alpha$ the apparent transfer coefficient. The subscripts, 1 and 2 , indicate reactions 1 and 2 , respectively. The superscript $\bigcirc$ indicates the value at the electrode surface.

At steady state, electrode reaction rates are related to the mass transfer rates of the dissolved oxygen and peroxide ion to or from the electrode surface.

$$
\begin{aligned}
& -i_{1} / 2 \boldsymbol{F}=k_{m A}\left(C_{A}^{\infty}-C_{A}^{\circ}\right) \\
& -i_{1} / 2 \boldsymbol{F}-\left(-i_{2} / 2 \boldsymbol{F}\right)=k_{m B}\left(C_{B}^{\circ}-C_{B}^{\infty}\right)
\end{aligned}
$$

where $k_{m}$ is the liquid-solid mass transfer coefficient. The total current density $i$ is obtained as follows.

$$
-i=-i_{1}+\left(-i_{2}\right)
$$

By eliminating $C_{A}^{\circ}$ from Eqs. (5) and (7),

$$
\frac{-i_{1}}{2 \boldsymbol{F}}=\frac{k_{A} C_{A}^{\infty} \exp \left(-\alpha_{1} \boldsymbol{F} \eta / \boldsymbol{R} T\right)}{1+\left(k_{A} / k_{m A}\right) \exp \left(-\alpha_{1} \boldsymbol{F} \eta / \boldsymbol{R} T\right)}
$$

Also, by eliminating $C_{B}^{\circ}$ from Eqs. (6) and (8),

$$
\frac{-i_{2}}{2 \boldsymbol{F}}=\frac{\left(-i_{1} / 2 \boldsymbol{F}+k_{m B} C_{B}^{\infty}\right)\left(k_{B} / k_{m B}\right) \exp \left(-\alpha_{2} F \eta / R T\right)}{1+\left(k_{B} / k_{m B}\right) \exp \left(-\alpha_{2} \boldsymbol{F} \eta / R T\right)}
$$

By substituting Eqs. (10) and (11) into Eq. (9), and replacing $\eta$ by $\left(\eta_{i}-\Delta E\right)$, the total current density of the reduction of oxygen is given as follows:

$$
-i / 2 \boldsymbol{F} k_{m A} C_{A}=\gamma_{1}\left\{1+\left(1+\Lambda / \gamma_{1}\right) \gamma_{2}\right\}
$$

where

$$
\left.\begin{array}{c}
\gamma_{1}=\frac{\left(k_{A} / k_{m A}\right) C_{V}^{-\alpha_{1} / 2} \exp \left(-\alpha_{1} \boldsymbol{F} \eta_{i} / \boldsymbol{R} T\right)}{1+\left(k_{A} / k_{m A}\right) C_{V}^{-\alpha_{1} / 2} \exp \left(-\alpha_{1} \boldsymbol{F} \eta_{i} / \boldsymbol{R} T\right)} \\
\gamma_{2}=\frac{\left(k_{B} / k_{m B}\right) C_{V}^{-\alpha_{2} / 2} \exp \left(-\alpha_{2} \boldsymbol{F} \eta_{i} / \boldsymbol{R} T\right)}{1+\left(k_{B} / k_{m B}\right) C_{V}^{-\alpha_{2} / 2} \exp \left(-\alpha_{2} \boldsymbol{F} \eta_{i} / \boldsymbol{R} T\right)} \\
C_{V}=C_{A i}^{\infty} C_{B}^{\infty} / C_{A}^{\infty} C_{B i}^{\infty}, \quad A=k_{m B} C_{B}^{\infty} / k_{m A} C_{A}^{\infty}
\end{array}\right\}
$$

\subsection{Concentration distribution of dissolved oxygen in packed-bed electrode}

The concentration of dissolved oxygen decreases along the liquid flow in the bed since the dissolved oxygen is consumed by reaction 1. A differential mass balance of dissolved oxygen in the bed gives Eq. (14), if plug flow is assumed and the axial and lateral dispersions of dissolved oxygen are negligible:

$$
-U_{L} \partial C_{A}^{\infty} / \partial z=a_{p}\left(-i_{1}\right) / 2 \boldsymbol{F}=a_{p} k_{m A} C_{A}^{\infty} \gamma_{1}
$$

where $U_{L}$ is the superficial liquid velocity and $a_{p}$ the effective specific surface area available for electrode reaction.

The boundary condition for Eq. (14) is

$$
C_{A}^{\infty}=C_{A 0}^{\infty} \quad \text { at } \quad z=0
$$

where $C_{A 0}^{\infty}$ is the concentration of dissolved oxygen at the bed inlet.

1.5 Electric potential profile in packed-bed electrode

The electric potential varies in the $x$ and $z$ directions of the bed (shown in Fig. 1) due to ohmic loss along the current flow and concentration change along the liquid flow. Based on the two-dimensional two-phase model ${ }^{6,15)}$ of the particulate electrode, the electric potential profile in the solution phase is given by the following equation, if the potential $\phi_{P}$ of the particle phase is assumed constant:

$$
\partial^{2} \phi_{S} / \partial x^{2}+\partial^{2} \phi_{S} / \partial z^{2}=a_{p}(-i) / \kappa_{e f f, s}
$$

where $\phi_{S}$ is the potential of the solution phase and $\kappa_{\text {eff }, s}$ the effective conductivity in the solution phase.

With the relation of $\eta=\phi_{P}-\phi_{S}-E_{e}$,

$$
\partial^{2}(-\eta) / \partial x^{2}+\partial^{2}(-\eta) / \partial z^{2}=a_{p}(-i) / \kappa_{e f f, s}
$$

By ignoring the reaction on the feeder electrode, the boundary conditions are given as follows. 


$$
\begin{array}{ll}
-\eta=-\eta_{i b}+\Delta E & \text { at } \quad x=0 \\
\partial(-\eta) / \partial x=0 & \text { at } \quad x=L \\
\partial(-\eta) / \partial z=0 & \text { at } \quad z=0 \text { and } H
\end{array}
$$

where $\eta_{i b}$ is the initial bed overpotential controlled at $x=0, L$ the bed depth and $H$ the bed height.

The numerical calculation of the successive overrelaxation method gives the overpotential profiles in the bed. ${ }^{* 1}$

\section{Experimental}

\subsection{Kinetics of electrode reaction}

The operational conditions were as described below, i.e., the catholyte was $1 \mathrm{~mol} \cdot \mathrm{dm}^{-3} \mathrm{KCl}$ plus $0.01 \mathrm{~mol} \cdot \mathrm{dm}^{-3} \mathrm{NaOH}$ solution, the anolyte $1 \mathrm{~mol}$. $\mathrm{dm}^{-3} \mathrm{NaOH}$ solution and reaction temperature $288 \mathrm{~K}$. The kinetics of electroreduction of the dissolved oxygen was examined with a rotating disk electrode, shown in Fig. 2. A graphite plate cathode (EG-38, Nippon Carbon) of $10 \mathrm{~mm}$ diameter was mounted in a polyacrylate disk of $40 \mathrm{~mm}$ diameter. A nickel plate was used as anode. A cation exchange membrane (Selemion CMV) was used to separate the cathode compartment from the anode compartment. The concentration of dissolved oxygen was kept at the saturated value by sparging oxygen gas into the catholyte. Current densityoverpotential curves at steady state were measured at various rotation speeds.

\subsection{Packed-bed electrode reactor}

The details of the packed-bed electrode reactor are shown in Fig. 1. Graphite particles were $1.5 \mathrm{~mm}$ in mean diameter and $44.7 \mathrm{~g}$ of particles (dry basis) was packed in the bed. Oxygen gas was sparged into the catholyte tank, and the catholyte and the anolyte were recycled between the respective tanks and the packedbed electrode reactor. ${ }^{2}$ The cathode compartment was separated from the anode compartment by a cation exchange membrane (Selemion CMV, Asahi Glass). Electrolysis was carried out by the constant potential method. The overpotential was controlled at the level of the membrane with a Luggin capillary and is designated the initial bed overpotential $\eta_{i b}$. At a reaction time of $2 \mathrm{hr}$ for various values of initial bed overpotential, the current, the concentrations of hydrogen peroxide and the dissolved oxygen at the bed inlet and outlet were measured. At the same time, the local overpotential was measured with Luggin capillaries of $3 \mathrm{~mm}$ outer diameter, inserted in the bed at the levels of $z=1,5$ and $9 \mathrm{~cm}$, as shown in Fig. 1 .

\subsection{Potential step method}

The effective specific surface area $a_{p}$ available for

*1 see Appendix 1.

*2 Schematic diagram of the experimental apparatus is shown elsewhere. ${ }^{16}$

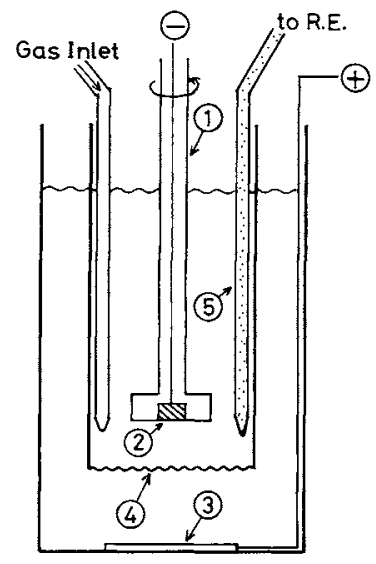

(1)Rotating disk electrode (2) Cathode (Graphite) (3) Anode (Ni) (4) Membrane (5) Luggin capillary

Fig. 2. Rotating-disk electrode.

electrode reaction in the packed-bed electrode was estimated by the potential step method. ${ }^{4,14,18)}$ Before each run, the dissolved oxygen in the catholyte was desorbed by sparging nitrogen gas to prevent the dissolved oxygen from contributing to the electric current by the Faradaic reaction. Firstly, a onecompartment electrolyzer, which consisted of a graphite cathode having an effective surface area of $1.99 \mathrm{~cm}^{2}$ and a nickel anode, was used to obtain the double-layer capacity of the graphite plate. Secondly, the packed-bed electrode reactor examined. The potential step generated with a function generator (HB107A, Hokuto Denko) and a potentiostat (HA-310, Hokuto Denko) was applied to the working graphite electrode. The transient current response to a potential step was sampled every $0.1 \mathrm{~ms}$ with a digital memory (DM-305, Iwatsu Denshi) and monitored with a synchroscope (SS-5510, Iwatsu Denshi).

\section{Results and Discussion}

\subsection{Kinetics of electrode reaction}

Figure 3 shows that the polarization curves at steady state for the rotating disk electrode express well the characteristics of the successive and competitive electrode reactions. The values of $k_{A}, k_{B}, \alpha_{1}$ and $\alpha_{2}$ and the ratio of $k_{m B} / k_{m A}$ were determined from analyses of the polarization curves. The first limiting current density $\left(-i_{1 L}\right)$ shown in Fig. 3 corresponds to the diffusion rate of the dissolved oxygen to the electrode surface, as expressed by Eq. (7) with $C_{A}^{\circ}=0$.

$$
-i_{1 L} / 2 \boldsymbol{F}=k_{m A} C_{A}^{\infty}
$$

$\left(-i_{1 L}\right)$ values shown in Table 1 were experimentally obtained from $(-i)$ values at the inflection points of the polarization curves. These values were in accordance with those calculated from the Levich 
Table 1. Kinetic properties obtained from polarization curves of rotating-disk electrode

\begin{tabular}{lccccccc}
\hline $\begin{array}{c}\omega \\
{\left[\mathrm{rad} \cdot \mathrm{s}^{-1}\right]}\end{array}$ & $\begin{array}{c}\left(-i_{1 L}\right) \\
{\left[\mathrm{A} \cdot \mathrm{m}^{-2}\right]} \\
\text { Estimated }\end{array}$ & $\begin{array}{c}k_{m A} \times 10^{5} \\
{\left[\mathrm{~m} \cdot \mathrm{s}^{-1}\right]}\end{array}$ & $\begin{array}{c}k_{m A} / k_{A} \\
{[-]}\end{array}$ & $\begin{array}{c}k_{A} \times 10^{7} \\
{\left[\mathrm{~m} \cdot \mathrm{s}^{-1}\right]}\end{array}$ & $\begin{array}{c}k_{m B} / k_{B} \\
{[-]}\end{array}$ & $\begin{array}{c}k_{B} \times 10^{9} \\
{\left[\mathrm{~m} \cdot \mathrm{s}^{-1}\right]}\end{array}$ \\
\hline 34.1 & 10.12 & 11.14 & 4.33 & 86.0 & 5.04 & 1030 & - \\
23.7 & 8.27 & 9.29 & 3.54 & 72.0 & 4.92 & 940 & 1.60 \\
13.5 & 6.42 & 7.00 & 2.75 & 57.0 & 4.82 & 670 & - \\
\hline
\end{tabular}

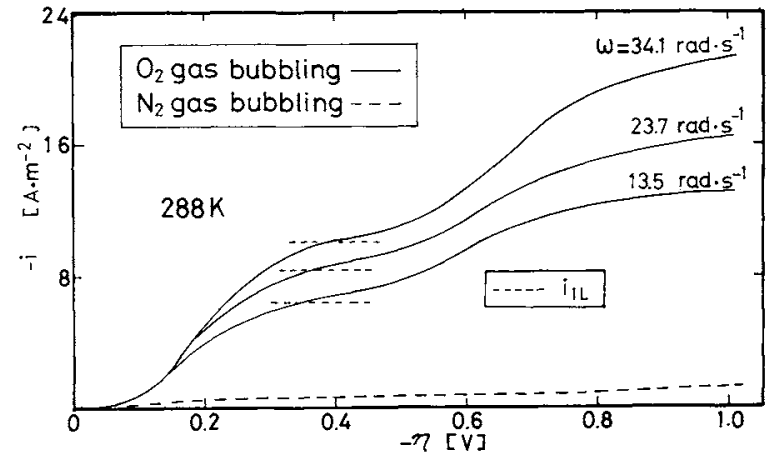

Fig. 3. Polarization curves for reduction of oxygen in rotating-disk electrode.

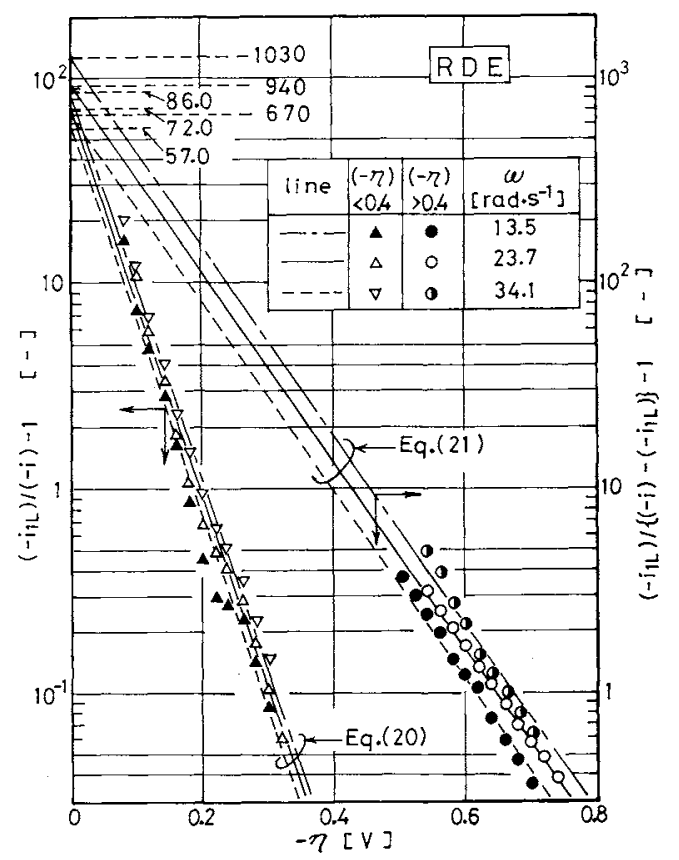

Fig. 4. Arrangement of polarization curves for determination of electrode reaction kinetics of oxygen.

equation, ${ }^{10)}$ as shown in Table $1 . k_{m A}$ were calculated from Eq. (19) by using $\left(-i_{1 L}\right)$ and $C_{A}^{\infty}$ values. Since reaction 2 was negligibly small below the negative overpotential where the current density approached the first limiting one, the current density below the first limiting one was equivalent to the current density due to reaction 1 . By taking a ratio of Eq. (10) to Eq. (19) and replacing $\left(-i_{1}\right)$ to $(-i)$, $\ln \left\{\left(-i_{1 L}\right) /(-i)-1\right\}=\ln \left(k_{m A} / k_{A}\right)-\alpha_{1} F(-\eta) / R T$

Semi-log plots of $\log \left\{\left(-i_{1 L}\right) /(-i)-1\right\}$ vs. $(-\eta)$ in the range of $(-\eta)=0.1-0.4$ give straight lines, as shown in Fig. 4. From the intersects of the lines, $\left(k_{m A} / k_{A}\right)$ were obtained, and $k_{A}$ value was determined by $\left(k_{m A} / k_{A}\right)$ and $k_{m A}$ values. The average value of $k_{A}$ was obtained as $4.93 \times 10^{-7} \mathrm{~m} \cdot \mathrm{s}^{-1}$. From the slope of the line, $\alpha_{1}$ was calculated as 0.546 , which was in accordance with $0.5-0.6$ by Brezina et al. ${ }^{3)}$ The kinetics of reaction 2 was analysed by the polarization curves in the range of $(-\eta)>0.4 \mathrm{~V}$, where reactions 1 and 2 occur consecutively. Equation (11) was transformed into Eq. (21) by assuming $C_{B}^{\infty}=$ 0 and using the relation $\left(-i_{2}\right)=(-i)-\left(-i_{1 L}\right)$ :

$$
\begin{gathered}
\ln \left[\left\{2\left(-i_{1 L}\right)-(-i)\right\} /\left\{(-i)-\left(-i_{1 L}\right)\right\}\right] \\
=\ln \left(k_{m B} / k_{B}\right)-\alpha_{2} \boldsymbol{F}(-\eta) / \boldsymbol{R} T
\end{gathered}
$$

Figure 4 also shows that the semi-log plots of $\log \left[\left\{2\left(-i_{1 L}\right)-(-i)\right\} /\left\{(-i)-\left(-i_{1 L}\right)\right\}\right]$ vs. $(-\eta)$ give straight lines in the range of $(-\eta)>0.4 \mathrm{~V}$. By the same procedure as used for reaction $1,\left(k_{m B} / k_{B}\right)$ were determined and are shown in Table $1 . \alpha_{2}$ was calculated as 0.263 and was a little lower than the values of $0.3-$ 0.4 by Brezina $e t$ al. ${ }^{3)}$

The value of $k_{m B}$ was determined by analysing the polarization curves shown in Fig. 5 for the catholyte to which hydrogen peroxide was added before experiments. The current density showed the second limiting current density $\left(-i_{2 L}\right)$ at $(-\eta) \simeq 0.9 \mathrm{~V}$. On the other hand, $\left(-i_{2 L}\right)$ is expressed by Eq. (22), which is deduced from Eq. (12) for the larger value of $(-\eta)$.

$$
-i_{2 L} / 2 \boldsymbol{F} k_{m A} C_{A}^{\infty}=2+k_{m B} C_{B}^{\infty} / k_{m A} C_{A}^{\infty}
$$

Substituting $k_{m A}$ given by Eq. (19) into Eq. (22) gives

$$
\left\{\left(-i_{2 L}\right)-2\left(-i_{1 L}\right)\right\} / 2 \boldsymbol{F}=k_{m B} C_{B}^{\infty}
$$

Then, $k_{m B}$ was obtained as $1.5 \times 10^{-6} \mathrm{~m} \cdot \mathrm{s}^{-1}$ for $\omega=$ $23.7 \mathrm{rad} \cdot \mathrm{s}^{-1}$ from the slope of the graphical relation between $\left\{\left(-i_{2 L}\right)-2\left(-i_{1 L}\right)\right\} / 2 F$ and $C_{B}^{\infty}$ shown in Fig. 6. $k_{B}$ was obtained as $1.6 \times 10^{-9} \mathrm{~m} \cdot \mathrm{s}^{-1}$ from the values of $\left(k_{m B} / k_{B}\right)$ and $k_{m B}$ at $\omega=23.7 \mathrm{rad} \cdot \mathrm{s}^{-1}$. The average value of $k_{m B} / k_{m A}$ was $3.98 \times 10^{-2}$ in the range of $\omega=13.5-34.1 \mathrm{rad} \cdot \mathrm{s}^{-1}$. 


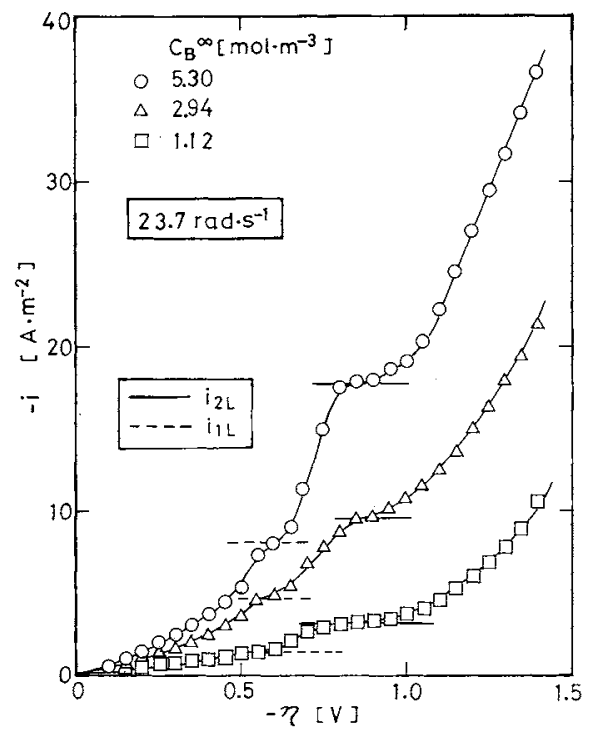

Fig. 5. Polarization curves for reduction of peroxide ion in rotating-disk electrode.

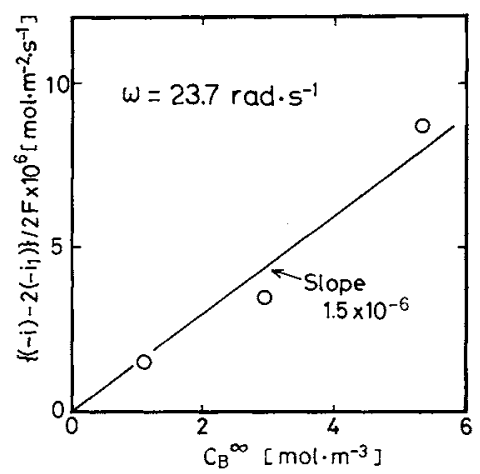

Fig. 6. Arrangement of polarization curves for determination of reduction kinetics of peroxide ion.

\subsection{Determination of $\kappa_{e f f, s}$ and $a_{p}$ of packed-bed electrode}

The effective conductivity $\kappa_{e f f, s}$ of the solution phase was determined with the following equation and the overpotential profile observed, where the concentration of the dissolved oxygen was assumed to be uniform through the bed.

$$
\kappa_{e f f, s}=-i_{b} /\left\{\mathrm{d}\left(-\eta_{i}\right) / \mathrm{d} x\right\}_{x=0}
$$

where $i_{b}$ was the average current density flowing through the bed.

From the result of the overpotential mentioned below, at $U_{L}=2.67 \mathrm{~cm} \cdot \mathrm{s}^{-1}$ and $\left(-\eta_{i b}\right)=0.2 \mathrm{~V}, \kappa_{e f f, s}$ was given as $3.03 \mathrm{~S} \cdot \mathrm{m}^{-1}$.

The double-layer capacity of the graphite plate was obtained by analysing the transient current response to a potential step. ${ }^{* 3}$ The relation between transient current $I$ and time $t$ is given by Eq. (25). ${ }^{* 4}$

$$
\ln |I|=\ln \left|\eta_{S T} / R_{S}\right|-t / R_{S} C_{F} A
$$

$* 3, * 4$ see Appendix 2 .

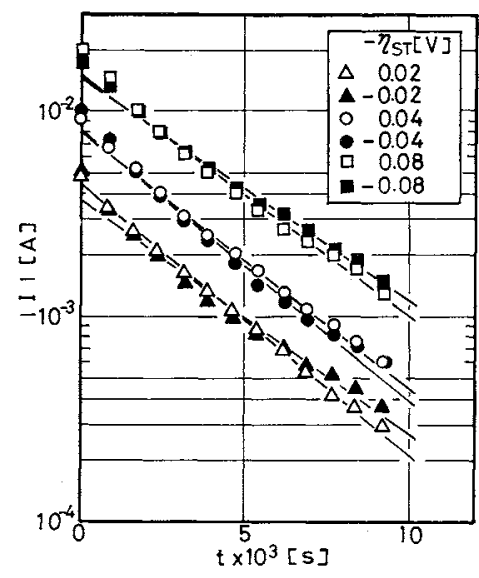

Fig. 7. Transient current of a graphite plate electrode.
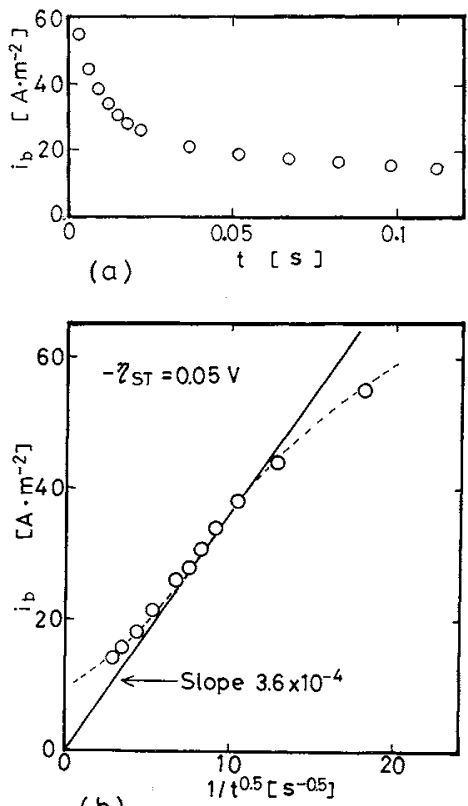

(b)

Fig. 8. Transient current density response to a potential step in packed-bed electrode.

Figure 7 shows the relations of $\log |I|$ vs. $t$ give straight lines. With the intersects $\log \left|\eta_{S T} / R_{S}\right|$ and the slope $\left(-1 / R_{S} C_{F} A\right)$ of the lines in Fig. 7, the doublelayer capacity $C_{F}$ was given as $3.55 \mathrm{~F} \cdot \mathrm{m}^{-2}$.

Figure 8(a) shows the transient current density $i_{b}$ for applying a potential step to a packed-bed electrode of graphite particles. Figure 8(b) shows that there exists a linear relation between $i_{b}$ and $t^{-0.5}$, as can be predicted by Eq. (A-13) in Appendix 3. From the slope of the straight line in Fig. 8(b) and Eq. (A-13), $\tau$ was determined as $0.177 \mathrm{~s}$. By using the values of $L=1 \mathrm{~cm}$, $\left(-\eta_{S T}\right)=0.05 \mathrm{~V}, \kappa_{e f f, s}=3.03 \mathrm{~S} \cdot \mathrm{m}^{-1}$ and $C_{F}=3.55$ $\mathrm{F} \cdot \mathrm{m}^{-2}$, the effective specific area $a_{p}$ available for electrode reaction in the packed-bed electrode was calculated as $1.52 \times 10^{3} \mathrm{~m}^{-1}$ from Eq. (A-11).

\subsection{Overpotential profile in packed-bed electrode}

The observed values of $\left(-\eta_{i}\right)$ and the theoretical ones predicted by Eq. (A-1) for the packed-bed 


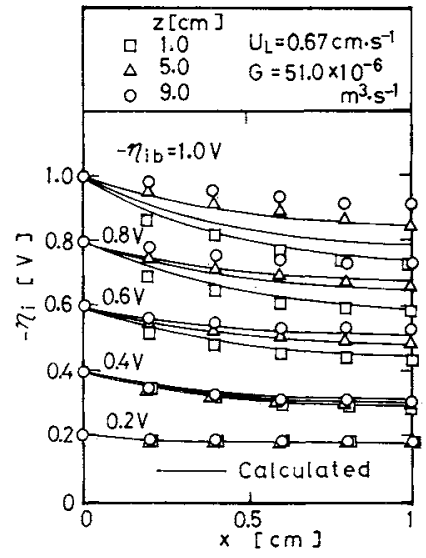

Fig. 9. Overpotential profiles in packed-bed electrode at $U_{L}=0.67 \mathrm{~cm} \cdot \mathrm{s}^{-1}$.

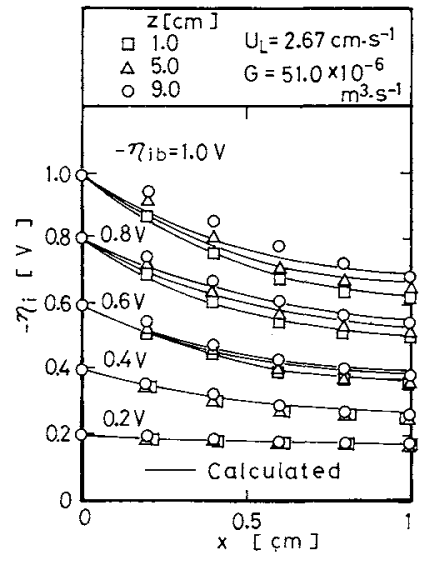

Fig. 10. Overpotential profiles in packed-bed electrode at $U_{L}=2.67 \mathrm{~cm} \cdot \mathrm{s}^{-1}$.

electrode are shown in Figs. 9 and 10. To estimate values for $k_{m A}$ in the bed, the correlation ${ }^{16)}$ of $k_{m A}$ experimentally obtained was used. The negative overpotential $\left(-\eta_{i}\right)$ decreased with increasing $x$ from the membrane where the initial bed overpotential $\left(-\eta_{i b}\right)$ was controlled with a Luggin capillary. The decrease in $\left(-\eta_{i}\right)$ value was more remarkable as $\left(-\eta_{i b}\right)$ increased. For $\left(-\eta_{i b}\right)=0.2 \mathrm{~V}$, the overpotential profiles at $U_{L}=0.67 \mathrm{~cm} \cdot \mathrm{s}^{-1}$ shown in Fig. 9 were little different from those at $U_{L}=2.67 \mathrm{~cm} \cdot \mathrm{s}^{-1}$ shown in Fig. 10, since the overall reaction rate of dissolved oxygen was controlled by electrode reaction at low values of $\left(-\eta_{i}\right)$. Meanwhile, in the range of $\left(-\eta_{i b}\right) \geqq 0.6 \mathrm{~V}$, the degrees of decrease in $\left(-\eta_{i}\right)$ with increasing $x$ were higher at $U_{L}=2.67$ $\mathrm{cm} \cdot \mathrm{s}^{-1}$ than those at $U_{L}=0.67 \mathrm{~cm} \cdot \mathrm{s}^{-1}$. This is due to the fact that the mass transfer rate of dissolved oxygen to the electrode surface and the overall reaction rate increase with increasing $U_{L^{-}}\left(-\eta_{i}\right)$ increased slightly with increasing distance $z$ from the bed inlet in the range of $\left(-\eta_{i b}\right) \geqq 0.6 \mathrm{~V}$. This is due to the fact that dissolved oxygen is consumed by the electrode reaction and its rate decreases with increasing distance $z$. The measured overpotentials at three

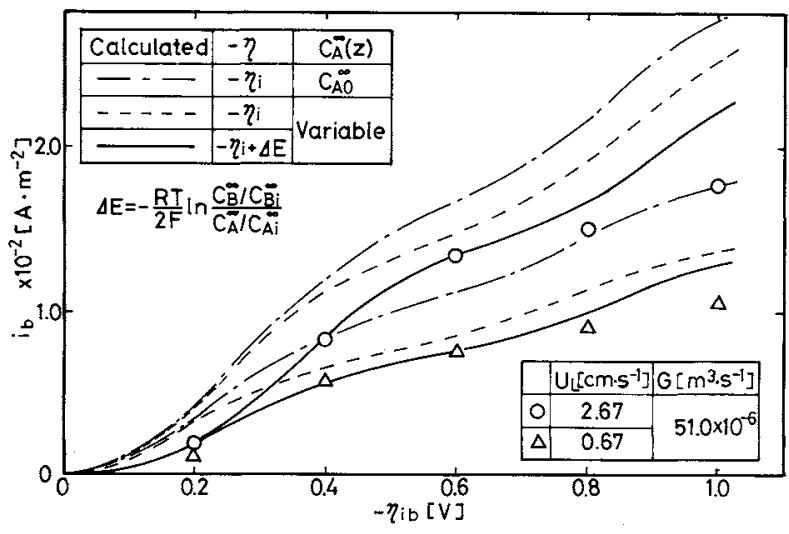

Fig. 11. Comparison between theoretical and observed values of polarization curves in packed-bed electrode.

different positions in the direction perpendicular to the $x$ and $z$ axes for $z=5 \mathrm{~cm}$ were almost the same, and the two-dimensional analyses applied were justified.

The theoretical values of $\left(-\eta_{i}\right)$ agree well with the observed ones in the range of $\left(-\eta_{i b}\right)=0.2-0.8 \mathrm{~V}$, but deviate slightly from the observed ones at $\left(-\eta_{i b}\right)=$ $1.0 \mathrm{~V}$, since water electrolysis occurred at high negative overpotential and the effective surface area available for electrode reaction was reduced by the adherence of hydrogen bubbles to the electrode surface.

\subsection{Polarization curves of packed-bed electrode}

The observed and theoretical values of the current density $i_{b}$ based on unit surface area of feeder electrode at various values of $\left(-\eta_{i b}\right)$ are shown in Fig. 11. The theoretical values of $i_{b}$ were obtained by integrating the local current density $i_{b, z}$ defined by Eq. (26).

$$
\begin{aligned}
& i_{b, z}=-\kappa_{e f f, s}\left\{\partial\left(-\eta_{i}\right) / \partial x\right\}_{x=0} \\
& i_{b}=\int_{0}^{H} i_{b, z} d z / H
\end{aligned}
$$

A comparison between the results in Fig. 2 for the rotating-disk electrode and those in Fig. 11 indicates that the stepwise curve characteristic of the successive electrode reaction is not clear for the packed-bed electrode. This is due to the fact that there is a potential distribution in the packed-bed electrode. The theoretical values of $i_{b}$ for considering the distribution of $C_{A}^{\infty}$ and $(-\eta)$ in the bed, the solid line in Fig. 11, agree well with the experimental ones. The dot-dashed and broken lines indicate the values of $i_{b}$ calculated, respectively, by assuming $C_{A}^{\infty}$ to be constant throughout the bed and using $\left(-\eta_{i}\right)$ as $(-\eta)$ and by only using $\left(-\eta_{i}\right)$ as $(-\eta)$. These lines do not coincide with $i_{b}$ experimentally observed.

\section{Conclusion}

The successive and competitive electrode reactions 
of electroreduction of oxygen in an alkaline solution were examined by a rotating-disk electrode of graphite, and the reaction rate constants and the apparent transfer coefficients for producing peroxide ion and reducing peroxide ion were determined.

The effective specific surface area of the packedbed electrode, available for electrode reaction, was determined by analysing the transient current response to a potential step.

A theoretical analysis for predicting the relation between the current density and the overpotential in the packed-bed electrode was made with a twodimensional two-phase model of the particulate electrode where the distributions of concentration of dissolved oxygen and the overpotential were considered. The observed values of the overpotential profile and the polarization curves of the packed-bed electrode agreed with the theoretical ones calculated by using the kinetic and reactor properties.

\section{Acknowledgment}

This work was supported partly by the Grants-in-Aid for Special Research on Environmental Science (58030014, 59030017) from the Ministry of Education, Science and Culture of Japan. The authors wish to express their thanks to Professor H. Inoue, Dept. of Chem. Eng., Univ. of Tokyo and the head of this project, for useful suggestions for this work.

\section{Appendix 1. Calculation of overpotential profile}

Substituting Eq. (4) into Eq. (17) and rearranging it by assuming $C_{B}^{\infty}$ to be constant give Eq. (A-1).

$$
\begin{aligned}
\frac{\partial^{2}\left(-\eta_{i}\right)}{\partial x^{2}}+\frac{\partial^{2}\left(-\eta_{i}\right)}{\partial z^{2}}= & \frac{\boldsymbol{R} T}{2 \boldsymbol{F}}\left\{\left(\frac{1}{C_{A}^{\infty}} \frac{\partial C_{A}^{\infty}}{\partial x}\right)^{2}+\left(\frac{1}{C_{A}^{\infty}} \frac{\partial C_{A}^{\infty}}{\partial z}\right)^{2}\right. \\
& \left.-\frac{1}{C_{A}^{\infty}} \frac{\partial^{2} C_{A}^{\infty}}{\partial x^{2}}-\frac{1}{C_{A}^{\infty}} \frac{\partial^{2} C_{A}^{\infty}}{\partial z^{2}}\right\}+\frac{a_{p}(-i)}{\kappa_{e f f, s}}
\end{aligned}
$$

In the numerical calculation of Eq. (A-1), the following conditions for the concentration of dissolved oxygen were assumed.

$$
\left.\begin{array}{lll}
\partial C_{A}^{\infty} / \partial x=0 & \text { at } & x=0 \\
\partial C_{A}^{\infty} / \partial z=0 & \text { at } & z=H
\end{array} \quad L\right\}
$$

With using Eqs. (4) and (A-2), the boundary conditions of Eq. (18) are simplified as follows.

$$
\left.\begin{array}{l}
-\eta_{i}=-\eta_{i b} \quad \text { at } \quad x=0 \\
\partial\left(-\eta_{i}\right) / \partial x=0 \quad \text { at } \quad x=L \\
\partial\left(-\eta_{i}\right) / \partial z=-\left(\boldsymbol{R} T / 2 \boldsymbol{F} C_{A}^{\infty}\right) \partial C_{A}^{\infty} / \partial z \quad \text { at } z=0 \\
\partial\left(-\eta_{i}\right) / \partial z=0 \quad \text { at } \quad z=H
\end{array}\right\}
$$

To solve Eqs. (14) and (A-1), Eqs. (14), (A-1), (A-2) and (A-3) are converted to a set of difference equations.

\section{Appendix 2}

The equivalent circuit for changing a double-layer on a graphite plate consisted of a series of the solution resistance $R_{S}$ and the double-layer capacity $C_{F}$ between the electrode and the solution. The circuit equation is as follows

$$
\eta(t)=R_{S} I(t)-\int I(t) d t / C_{F} A
$$

The boundary conditions for applying a potential step are as follows

$$
\left.\begin{array}{lll}
\eta(t)=0 & \text { at } & t<0 \\
\eta(t)=\eta_{S T} & \text { at } & t \geqq 0
\end{array}\right\}
$$

The analytical solution of Eq. (A-4) is

$$
I(t)=\left(\eta_{S T} / R_{S}\right) \exp \left(-t / R_{S} C_{F} A\right)
$$

\section{Appendix 3}

The one-dimensional current balance for charging the doublelayer capacity in the packed-bed electrode and neglecting Faradaic current is given as follows.

$$
\partial(-\eta) / \partial t=\left(\kappa_{e f f, s} / a_{p} C_{F}\right) \partial^{2}(-\eta) / \partial x^{2}
$$

The initial and boundary conditions are

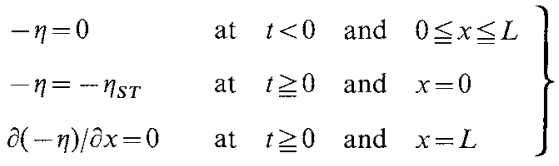

The observed current density $i_{b}$ through the bed is as follows.

$$
i_{b}=-\kappa_{e f f, s}\{\partial(-\eta) / \partial x\}_{x=0 .} .
$$

Solving Eq. (A-7) by the method of separation of variables leads to the following equation.

$$
\begin{aligned}
(-\eta) /\left(-\eta_{S T}\right)= & 1-\sum_{j=0}^{\infty}\left\{2(-1)^{j} / \pi(j+0.5)\right\} \\
& \times \exp \left\{-(j+0.5)^{2} \pi^{2} t / \tau\right\} \cos \{(j+0.5) \pi x / L\}
\end{aligned}
$$

where

$$
\tau=a_{p} C_{F} L^{2} / \kappa_{e f f, s}
$$

Then, from Eqs. (A-9) and (A-10),

$$
i_{b}=\left\{2 \kappa_{\text {eff }, \mathrm{s}}\left(-\eta_{S T}\right) / L\right\} \sum_{j=0}^{\infty} \exp \left\{-(j+0.5)^{2} \pi^{2} t / \tau\right\}
$$

Equation (A-12) is simplified at $t \ll \tau$,

$$
i_{b}=\kappa_{e f f, s}\left(-\eta_{S T}\right)(\tau / \pi t)^{0.5} / L
$$

\section{Nomenclature}

$A=$ surface area of electrode

$a_{p} \quad=$ effective specific surface area available for electrode reaction.

C

= concentration

$C_{F} \quad=$ double-layer capacity per unit surface area of electrode $\left[\mathrm{F} \cdot \mathrm{m}^{-2}\right]$

$C_{V}=$ variable defined by Eq. (13)

$E_{e} \quad=$ equilibrium potential

$\Delta E \quad=$ difference of equilibrium potential from initial one

$G$

$H$

$I$

$i$

$=$ Faraday's constant

= flow rate of oxygen in catholyte tank $\left[\mathrm{m}^{3} \cdot \mathrm{s}^{-1}\right]$

$=$ bed height

$=$ transient current

$=$ current density

$=$ average current density per unit surface area of feeder electrode in packed-bed electrode

$i_{b, z}=$ local current density defined by Eq. (26)

$i_{\mathrm{L}} \quad=$ limiting current density $\quad\left[\mathrm{A} \cdot \mathrm{m}^{-2}\right]$

$k=$ rate constant of electrode reaction $\quad\left[\mathrm{m} \cdot \mathrm{s}^{-1}\right]$

$k_{m} \quad=$ liquid-solid mass transfer coefficient $\quad\left[\mathrm{m} \cdot \mathrm{s}^{-1}\right]$

$L \quad=$ bed depth [m]

$\boldsymbol{R} \quad=$ gas constant $\quad\left[\mathrm{J} \cdot \mathrm{mol}^{-1} \cdot \mathrm{K}^{-1}\right]$

$R_{S} \quad=$ solution resistivity $[\Omega]$

$t \quad=$ time [s] 


\begin{tabular}{|c|c|c|}
\hline$U_{L}$ & $=$ superficial liquid velocity & {$\left[\mathrm{m} \cdot \mathrm{s}^{-1}\right]$} \\
\hline$x$ & $=$ distance from membrane & {$[\mathrm{m}]$} \\
\hline$z$ & $=$ distance from bed inlet & [m] \\
\hline$\alpha$ & $=$ apparent transfer coefficient & {$[-]$} \\
\hline$\gamma_{1}, \gamma_{2}$ & $=$ variables defined by Eq. (13) & {$[-]$} \\
\hline$\eta$ & $=$ overpotential & [V] \\
\hline$\eta_{i}$ & $\begin{aligned}= & \text { overpotential based on initial equilibrium } \\
& \text { potential }\end{aligned}$ & {$[\mathrm{V}]$} \\
\hline$\eta_{i, b}$ & $\begin{aligned}= & \text { initial bed overpotential controlled at level } \\
& \text { of membrane }\end{aligned}$ & [V] \\
\hline$\eta_{S T}$ & $\begin{aligned}= & \text { overpotential applied in potential step } \\
& \text { method }\end{aligned}$ & [V] \\
\hline$\kappa_{e f f, s}$ & $=$ effective conductivity in solution phase & {$\left[\mathrm{S} \cdot \mathrm{m}^{-1}\right]$} \\
\hline$A$ & $=$ variable defined by Eq. (13) & {$[-]$} \\
\hline$\phi$ & $=$ electrical potential & [V] \\
\hline$\tau$ & $=$ time defined by Eq. (A-11) & {$[s]$} \\
\hline$\omega$ & $=$ rotation speed & {$\left[\mathrm{rad} \cdot \mathrm{s}^{-1}\right]$} \\
\hline
\end{tabular}

〈Subscripts〉

\begin{tabular}{|c|c|}
\hline$A$ & $=$ dissolved oxyger \\
\hline$B$ & $=$ peroxide ion \\
\hline$i$ & $=$ initial value \\
\hline$P$ & $=$ particle phase \\
\hline$S$ & $=$ solution phase \\
\hline 0 & $=$ bed inlet \\
\hline 1 & $=$ reaction 1 \\
\hline 2 & $=$ reaction 2 \\
\hline
\end{tabular}

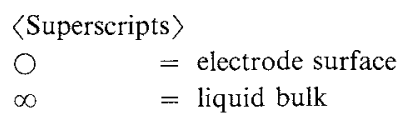

\section{Literature Cited}

1) Alkire, R. and R. Gould: J. Electrochem. Soc., 123, 1842 (1976).
2) Alkire, R. and R. Gould: J. Electrochem. Soc., 129, 293 (1982).

3) Brezina, M. and A. Hoffmanova: Collect. Czechoslov. Chem. Commun., 38, 985 (1973).

4) Brown, M. and F. Posey: J. Electrochem. Soc., 128, 306 (1981).

5) Enrique-Granados, M. A., D. Hutin and A. Stork: Electrochim. Acta, 27, 303 (1982).

6) Fedkiw, P. S.: J. Electrochem. Soc., 128, 831 (1981).

7) Goodridge, F., D. Holden, M. Murray and R. Plimley: Trans. Inst. Chem. Eng., 49, 128 (1971).

8) Kreysa, G.: Electrochim. Acta, 23, 1351 (1978).

9) Kusakabe, K., S. Morooka and Y. Kato: J. Chem. Eng. Japan, 14, 208 (1981).

10) Levich, V. G.: "Physicochemical Hydrodynamics," p. 69, Prentice-Hall (1962).

11) Newman, J.: "Electrochemical System," translated into Japanese by M. Takahashi et al:; "Denki Kagaku System," p. 207, Corona-sha (1976).

12) Newman, J. and C. W. Tobias: J. Electrochem. Soc., 109, 1183 (1962).

13) Paulin, M., D. Hutin and F. Coeuret: J. Electrochem. Soc., 124, 180 (1977)

14) Posey, F. and T. Morozumi: J. Electrochem. Soc., 113, 176 (1966).

15) Stork, A., M. A. Enrique-Granados and M. Rogers: Electrochim. Acta, 27, 293 (1982).

16) Sudoh, M., H. Kitaguchi and K. Koide: to be printed in $J$. Chem. Eng. Japan.

17) Sudoh, M., J. Yugami and T. Shirotsuka: J. Chem. Eng. Japan, 17, 152 (1984).

18) Tiedemann, W. and J. Newman: J. Electrochem. Soc., 122, 70 (1975).

19) Yoshizawa, S., Z. Takehara and Z. Ogumi: Bull. Chem. Soc. Japan, 49, 3372 (1976).

(Presented at the 49th Annual Meeting of The Society of Chemical Engineers, Japan at Nagoya, April 5, 1984.) 